\title{
El español jurídico: propuesta de intervención en el aula de español con fines específicos
}

\author{
Legal Spanish: intervention proposal in the Spanish for specific purposes \\ class
}

Esther Sanz i Vilar · (1) https://orcid.org/0000-0002-9555-4668

Universidad Internacional de la Rioja

Avenida de la Paz, $137 \cdot 26006 \cdot$ Logroño $\cdot$ La Rioja (Spain)

Santiago Sevilla-Vallejo ${ }^{1}$ - (D) https://orcid.org/0000-0002-9017-4949

Universidad de Salamanca

Paseo de Canalejas, $169 \cdot 37008 \cdot$ Salamanca (Spain)

\section{RESUMEN}

Es bien sabido que para el correcto aprendizaje de una lengua, además de conocer las reglas gramaticales, el léxico y demás normas formales, también se debe conocer la cultura relacionada con la misma. La cuestión principal cuando se trata este asunto es qué cultura llevar al aula, pregunta que se acentúa cuando tratamos las lenguas de especialidad. El presente artículo trata de definir qué son las lenguas de especialidad en general y de presentar las características del español jurídico en concreto. Además, y en consonancia con lo mencionado anteriormente, también se trata la "cultura profesional", es decir, los usos y costumbres que tienen los operadores jurídicos españoles en el ejercicio de su profesión.

Además de este enfoque teórico, también se plantea una propuesta de intervención, concretamente, se trata de una unidad didáctica basada en un caso real de derecho penal. Esta propuesta incluye una serie de actividades variadas que tienen como objetivo trabajar contenidos gramaticales, léxicos, de tipología discursiva propios del español jurídico así como de la cultura profesional jurídica. Estos contenidos se presentan a través de un caso real que acompaña al alumno desde el principio hasta el final de la unidad didáctica y del cual forma parte activamente, ya sea como acusación o como defensa.

Palabras clave: cultura, español específico, español jurídico, cultura profesional, propuesta de intervención.

\section{ABSTRACt}

It is commonly known that in order to learn a language correctly, knowledge of grammar rules, vocabulary and other formal rules must be accompanied by knowledge of the associated culture. The main consideration when it comes to dealing with this matter is which culture to bring into the classroom. This issue is more noticeable when it comes to specialty languages. This article will try to establish what specialty languages are in general, and to introduce the main characteristics of legal Spanish in particular. Moreover, in line with the above observation, the "professional culture" in this case, the customs and practices of legal practitioners in the course of their daily work, will be also addressed.

In addition to this theoretical approach, this article contains an intervention proposal, concretely a didactic unit concerning a criminal law case. This proposal includes a range of varied activities, the goal of which is to focus on legal Spanish grammar, lexicon and discursive typology contents as well as legal professional culture. All the mentioned contents are introduced through a real case

Corresponding author $\cdot$ Email: santiagosevilla@usal.es 
study, which guides the student from the beginning to the end of the didactic unit. Moreover, the student takes part as an active agent in the case for the prosecution or defense.

Keywords: culture, Spanish for specific purposes, legal Spanish, professional culture, intervention proposal.

\section{Introducción}

Es bien sabido que actualmente en la enseñanza de una lengua extranjera, lengua y cultura van de la mano (Tong, 2013). A raíz de este indisociable binomio diversos autores se han planteado varias cuestiones tales como, por ejemplo, ¿qué se entiende por cultura?, ¿qué cultura debería enseñarse?, ¿qué actividades y materiales son los más adecuados para llevar al aula ELE?

Teniendo en cuenta el contexto universitario en el que el contenido de los programas es estricto, así como el tiempo y los recursos que se pueden invertir, surge la duda de si vale la pena introducir la cultura en el aula. García y Massaguer (2011: 225) consideran que sí debido a que en caso de no hacerlo podría darse el supuesto de estudiantes que acabaran su formación universitaria siendo lingüísticamente competentes, pero no siéndolo comunicativamente.

Además, en muchas ocasiones los alumnos que estudian español como lengua extranjera en la universidad son estudiantes de otros campos de estudio tales como la Medicina, el Derecho, la Farmacia o la Educación, y por ello resulta interesante ofrecer cursos en los que se proporcionen contenidos lingüísticos y culturales especializados en una rama de estudio. Es en este momento en el que entra en juego la enseñanza de español con fines específicos, definida por el "Diccionario de términos clave de ELE" (2008) como «(el) conjunto de usos del español empleado en cada uno de estos ámbitos (profesionales que trabajan en determinados contextos laborales o expertos que desarrollan su actividad en una disciplina académica concreta); según el campo profesional o académico estudiado». Este tipo de enseñanza del español ha tenido más importancia en los últimos años debido a la creciente popularidad de programas de intercambio, como el programa Erasmus, o debido a la creciente demanda del español como lengua extranjera para la comunicación profesional en contextos internacionales (Aguirre Beltrán, 1998, citada en Rodríguez-Piñero y García, 2009: 909).

Como se verá más adelante, la enseñanza de español con fines específicos reviste de cierta singularidad. Si bien es cierto que su finalidad es la enseñanza del español como lengua extranjera, uno de los objetivos principales de este tipo de enseñanza es proporcionar herramientas y estrategias a los alumnos para que estos puedan desenvolverse por sí mismos en contextos académicos y/o profesionales. Asimismo, cabe poner de relieve que el perfil del estudiante de lengua de especialidad es diferente de aquel de lengua general (Pastor 2010: 81).

El "Diccionario de términos clave en ELE" (2008) recomienda que el proceso de enseñanza-aprendizaje se conciba como una «inmersión en situaciones comunicativas especializadas». Esta última idea es de especial relevancia, ya que el desarrollo de la competencia comunicativa en la enseñanza de español con fines específicos, sea cual sea el campo profesional o académico, es vital. Es recomendable una aproximación a través de la presentación de situaciones reales, del uso de textos auténticos, de interacciones comunicativas reales o exposiciones en formato textual u oral que se esperarían de un profesional. El uso de estos materiales reales permite acercar a los estudiantes a una cultura específica, a la "cultura profesional". 


\section{Marco teórico}

\section{1. ¿Qué se entiende por cultura?}

Qué es la cultura ha sido una cuestión ampliamente debatida en la bibliografía. Este es un concepto para el que no hay una definición unitaria, de hecho, es una noción flexible que se puede entender de diversas formas en función de la perspectiva que se adopte (Williams, 1983: 87). Sin embargo, el presente artículo va a tomar como referencia la definición dada por Miquel y Sans (2004). Estas autoras indican que Porcher (1986) define cultura como «modo de clasificación, es la ficha de identidad de una sociedad, son los conocimientos de los que dispone; son las opiniones (filosóficas, morales, estéticas...) fundadas más en convicciones que en un saber». Asimismo, añaden que «la cultura es, ante todo, una adhesión afectiva, un cúmulo de creencias que tienen fuerza de verdad y que marcan, en algún sentido, cada una de nuestras actuaciones como individuos miembros de una sociedad».

Además, las autoras mencionadas clasifican la cultura en: "cultura con mayúsculas", "cultura a secas" y "kultura con k". La clasificación de la cultura en diversos grupos genera dudas sobre qué cultura debería llevarse al aula, cuál de estos tipos es el que más interesa a los alumnos y cuál es necesario para el correcto aprendizaje de una lengua extranjera. Bien, tal como apuntan Miquel y Sans (2004), el profesor de ELE debería esforzarse en enseñar a sus alumnos la parte central, la cultura que denominan "cultura a secas" y definen como aquella que «comprende todo lo compartido por los ciudadanos de una cultura» y a través de la cual se accede a los otros dos tipos de cultura, que engloban, entre otros, la lectura de poemas, la redacción de ciertos textos, la identificación social o cultural de un interlocutor y la actuación lingüística correcta. Concretamente, la cultura que se va a tratar en la presente propuesta es la cultura profesional jurídica, que encaja perfectamente en la definición de "cultura con c", dado que los profesionales del derecho tienen unas costumbres, tradiciones y formas de hacer específicas de su ámbito.

\subsubsection{La relación entre lengua, cultura y competencia comunicativa}

Además de definir qué se entiende por cultura, cabe destacar que lengua, cultura y competencia comunicativa son conceptos íntimamente relacionados entre sí.

Por un lado, tal como se ha avanzado y tal como indican diversos autores, la enseñanza de una lengua no tiene sentido sin la enseñanza de la cultura correspondiente a la lengua meta. Paricio (2014: 216) indica que «llevar una lengua extranjera al aula significa poner en contacto al alumnado con un mundo culturalmente diferente al propio». Asimismo, Miquel y Sans (2004) consideran que las pautas culturales provocan determinados comportamientos o intercambios comunicativos y estos, a su vez, hacen que los individuos utilicen ciertas formas lingüísticas. De hecho, el "Diccionario de términos clave en ELE" (2008), relaciona la competencia comunicativa con la lengua y la cultura y la define como la «capacidad de una persona para comportarse de manera eficaz y adecuada en una determinada comunidad de habla; ello implica respetar un conjunto de reglas que incluye tanto las de la gramática y los otros niveles de la descripción lingüística (léxico, fonética, semántica) como las reglas de uso de la lengua, relacionadas con el contexto socio-histórico y cultural en el que tiene lugar la comunicación».

El "Marco Común Europeo de Referencia" (2002: 7), en adelante "MCER", indica que para desarrollar la competencia comunicativa se tiene que ir más allá de lo estrictamente lingüístico, es decir, se tienen que abordar otras dimensiones como por ejemplo la sociocultural. En este sentido, Miquel y Sans (2004) opinan que la única 
manera de potenciar la competencia comunicativa del estudiante de lengua extranjera es mediante la consideración de la competencia cultural como un elemento básico de la enseñanza de la lengua. En definitiva, la lengua es la expresión de la cultura, por lo que el alumno debe aprender aspectos culturales para adaptarla a la situación comunicativa en la que se encuentre.

Todo lo anterior conlleva, no solo el desarrollo de la competencia comunicativa, sino también el de la competencia intercultural, es decir, «el conocimiento, la percepción y la comprensión de la relación entre el "mundo de origen" y el "mundo de la comunidad objeto de estudio"» (MCER, 2002: 101). Esto capacita a los alumnos a utilizar diferentes lenguas y conocer las culturas relacionadas con las mismas.

\subsection{El español con fines específicos}

El "Diccionario de términos clave en ELE" (2008) define enseñanza de español con fines específicos (en adelante "EFE") como:

Procesos de enseñanza-aprendizaje que facilitan el dominio de la comunicación especializada, esto es, la lengua que utilizan los profesionales que trabajan en un determinado contexto laboral o los expertos que desarrollan su actividad en una disciplina académica concreta. Se denomina Español con Fines Específicos (EFE) al conjunto de usos del español empleado en cada uno de estos ámbitos; según el campo profesional o académico estudiado, se distingue, por ejemplo, entre Español de los negocios, Español del turismo, Español jurídico, Español de las relaciones internacionales o Español de la medicina, entre otros.

Otros autores han definido qué es el EFE y han investigado cuáles son sus características. Cabré (1993), citada en Gutiérrez (2011: 151), señala que algunas de las características del EFE son: «a) se trata de conjuntos “especializados”, ya sea por la temática, la experiencia, el ámbito de uso o los usuarios; b) se presentan como un conjunto con características interrelacionadas, no como fenómenos aislados; c) mantienen la función comunicativa como predominante, por encima de otras funciones complementarias». Se puede apreciar que una de las características más relevantes del EFE es su función comunicativa. Concretamente, cabe destacar la importancia de uno de sus componentes, la competencia pragmática. Por un lado, según Calahorro (2015: 76) se pueden distinguir los diversos tipos de EFE a través de un análisis pragmático del mismo. Por otro lado, Méndez y Gil del Moral (2019: 15) indican que la pragmática influye en el componente cultural de la clase de EFE, es decir, permite evidenciar que cualquier interacción está enmarcada tanto en un entorno lingüístico como en uno cultural. Estas autoras advierten que el desconocimiento del aspecto cultural de una interacción puede llegar a provocar un malentendido o puede impedir el objetivo comunicativo perseguido. Por lo tanto, uno de los objetivos principales de la enseñanza de EFE es «proporcionar la competencia comunicativa necesaria para desenvolverse en diferentes contextos profesionales» (Rodríguez-Piñero y García, 2009: 921-922).

Otras características comunes del lenguaje especializado son, según el profesor Moreno Fernández, citado en Vilches y Sarmiento (2016: 22), su utilidad como instrumento de comunicación formal y funcional entre especialistas; matización de la gramática común; gran especificidad léxica, muchas veces con uso de términos exclusivos; estilos marcados por la impersonalidad y poca implicación afectiva debido a su carácter formal; subordinación de lo estético y expresivo a la eficacia comunicativa; predominancia del discurso escrito sobre el oral. A este respecto, Calahorro (2015: 75) recuerda que el "Diccionario de lingüística Aplicada y Enseñanza de Lenguas" (1997) indica que las lenguas de especialidad «se utilizan en ciertos tipos de comunicación particulares y restringidos y que contienen rasgos léxicos, gramaticales y de otras índoles, diferentes de los de la lengua común». Asimismo, García (2016: 37) destaca la presencia de tecnolectos en las lenguas de especialidad. En 
esta línea, Gómez de Enterría (2009: 45) indica que «las lenguas de especialidad son patrimonio de los especialistas que las emplean para poner en práctica la comunicación científica, tecnológica y profesional».

Todos estos aspectos peculiares de las lenguas de especialidad permiten identificar a sus «usuarios como miembros de una comunidad científica o profesional con un estilo comunicativo propio» (Gómez de Enterría, 2009: 46). Las comunidades identificables, es decir, los ámbitos a los que sería aplicable el EFE son incontables, sin embargo, algunos ejemplos son «el español para negocios y empresas, para el turismo, para la salud y la medicina, para el derecho y la justicia, para la diplomacia y para el ejército» (Méndez y Gil del Moral, 2019: $15)$.

De lo mencionado anteriormente se deriva que la docencia en EFE diverge de la docencia en ELE. En este sentido Calahorro (2015) y Sabater (2019), indican los rasgos diferenciadores y los que dificultan este tipo de enseñanza: a) la docencia en EFE parte de una enseñanza especializada; b) el perfil de los alumnos de EFE es más concreto que el de los estudiantes de ELE en general; c) el rol del profesor de EFE es diferente al del profesor de ELE debido a la necesidad de enfrentarse a una especialidad ajena; d) existe una escasez de materiales didácticos disponibles para llevar al aula EFE.

Respecto al perfil de los estudiantes de EFE, sea cual sea la especialidad, este es parecido (Calahorro, 2019: 79). Estos estudiantes tienen gran motivación, conocimientos específicos en la materia de especialidad y gran capacidad de observación, análisis y síntesis (Ainciburu y Suñén, 2019: 41) y estos son profesionales o estudiantes de un ámbito concreto de estudio con objetivos comunicativos muy específicos (Calahorro, 2015: $78)$.

La figura del profesor de EFE suscita gran interés, ¿cuál es el perfil que debería tener este profesor? Según Calahorro (2015: 79) el profesor de EFE puede ser un profesor de ELE con conocimientos específicos del ámbito de especialidad o un profesional de cierto ámbito con formación específica en ELE. Sin embargo, para Aguirre (2012) el profesor de EFE debería ser un especialista en lengua española con formación en ELE y cualificación específica como profesor especializado en EFE con conocimientos sobre el ámbito concreto, los procesos básicos de comunicación, sus particularidades y las dimensiones interculturales. Esta idea queda reforzada por Sabater (2019: 24), que indica que los profesores de EFE deben adquirir conocimientos sobre la materia de estudio además de ser especialistas en la lengua española.

Sin embargo, sea cual sea el perfil del profesor de EFE, este debe encargarse de suplir la falta de materiales disponibles, por los que los profesores de español especializado deben seleccionar, adaptar, modificar o incluso crear materiales para llevar al aula, teniendo en cuenta las necesidades del grupo concreto de estudiantes (Sabater, 2019: 20). Gómez de Enterría (2009), citada en Rodríguez-Piñero y García (2009: 922), indica que los cursos de EFE pueden tener una estructura estándar o unos objetivos precisos «diseñados a la carta para satisfacer necesidades comunicativas muy concretas». En este último caso se deben analizar las necesidades objetivas y subjetivas de los alumnos a través de herramientas tales como los cuestionarios, la observación en clase o los diarios de aprendizaje (Instituto Cervantes, 2012: 13). En todo caso, y tal como indican Chale (2002), citado en Gómez de Enterría (2009: 59), y el "Diccionario de términos clave en ELE" (2008), para crear materiales adecuados para este tipo de cursos se deben introducir en el aula muestras de lengua reales (Chale: 2002, citado en Gómez de Enterría, 2009: 59). 


\subsection{El español jurídico}

El español jurídico ${ }^{2}$ es un campo del lenguaje de especialidad que no goza de gran investigación debido a su complejidad (Méndez y Gil del Moral, 2019: 21). Las dificultades que presenta se deben a sus características peculiares como por ejemplo unos rasgos lingüísticos complejos, léxico especializado, oscurantismo, opacidad y arcaicismo del léxico, entre otras.

Como es generalmente sabido, el derecho es un ámbito muy cambiante en función de las diferentes jurisdicciones, no solo respecto a la legislación y las distintas regulaciones, sino también en la manera de actuar de sus profesionales. Además, en este punto cabe hacer un pequeño inciso sobre los dos grandes sistemas jurídicos existentes, el Civil Law, o derecho continental, en el que se enmarca el derecho español, y el Common Law, o derecho anglosajón. Debido a que las diferencias entre ambos sistemas son notables, el profesor de español jurídico deberá tener en cuenta el sistema en el que sus alumnos estudien o ejerzan el derecho.

\subsubsection{Rasgos lingüísticos diferenciadores}

Varios autores, Gutiérrez (2010), Alcaraz (2002, 16-17), Mora (2017), han identificado diferentes características del español jurídico, sin embargo, se puede observar que, a grandes rasgos, todos ellos están de acuerdo en que sus peculiaridades son: el uso de léxico especializado; el uso una sintaxis compleja, y en ocasiones oscura; y unos géneros discursivos particulares. Debido a que este tipo de español es muy diverso al español general como lengua extranjera, resulta interesante prevenir a los alumnos de que el español jurídico es más complejo que el español común. De esta manera, los estudiantes tendrán una predisposición más positiva y abierta ante el aprendizaje de esta especialidad.

En lo referente al léxico jurídico, este se caracteriza por el uso de tecnolectos (Bastidas, 2016: 26), uso de latinismos (ex novo, ab intestato, in dubio pro reo, petitum, etc.) y de palabras provenientes de otras lenguas como el griego, el inglés y el francés. Asimismo, Alcaraz (2002: 24-30), indica que algunas de las características de este lenguaje son el «gusto por lo altisonante y arcaizante, el apego a fórmulas estereotipadas y léxico relacional, creación de nuevos términos, redundancia expresiva léxica, inclinación hacia la nominalización y relexicación». Además, cabe destacar que esta terminología especializada puede ser tanto de uso común y generalizado, despido o denuncia, como exclusivamente jurídica, iuris tantum, ex nunc (Gutiérrez, 2010: 4).

Respecto a las construcciones gramaticales del español jurídico, Gutiérrez (2010: 4-5) indica que las más comunes en el lenguaje jurídico son: construcciones pasivas; cláusula ablativa o "ablativo absoluto"; futuro imperfecto de subjuntivo; sintagmas nominales largos; adjetivación valorativa de lo expresado en sintagmas nominales largos; modalidad deóntica y modo autoritario; y abuso del gerundio. Asimismo, Bastidas (2016: 2122) indica y desarrolla otros rasgos morfosintácticos particulares del español jurídico: a) sintaxis compleja en la que se usan oraciones largas en las que se quebranta la sucesión natural de las oraciones; b) uso de oraciones coordinadas y subordinadas con frecuentes incisos; c) uso del presente de indicativo con valor dispositivo; d) uso del futuro imperfecto de indicativo; e) uso del futuro imperfecto y perfecto de subjuntivo, caído en desuso en el español común; f) frecuencia en el uso de formas no personales como el gerundio y el participio; g) frecuencia de uso de la voz pasiva, asimismo caído en desuso en el español general; h) uso de perífrasis verbales tales como deber + infinitivo, tener que + infinitivo, haber de + infinitivo y poder + infinitivo, que expresan

El presente artículo se aborda desde un punto de vista del derecho español. 
obligación y posibilidad; i) uso de verbos de lengua, como por ejemplo negar, afirmar, declarar o predicar y verbos de negociación como desestimar, renunciar, desistir o anular; j) frecuencia de anteposición del adjetivo al sustantivo; k) uso de siglas cuyo significado es evidente para los juristas pero no para los receptores ajenos al derecho.

En relación con los géneros discursivos, en derecho existen abundantes tipos de géneros discursivos que tienen diferentes funciones, es decir, que responden a diferentes finalidades. Gutiérrez (2011: 155-160) propone la siguiente clasificación: a) discurso narrativo, habitual en los "antecedentes de hecho" ${ }^{3}$ de las sentencias judiciales, relata unos acontecimientos en orden cronológico, situando una acción en una localización espaciotemporal concreta, de manera que se puedan relacionar y deducir las causas y consecuencias de lo descrito. Es habitual el uso del pretérito indefinido, junto con el imperfecto o el pluscuamperfecto y del presente histórico; b) discurso descriptivo: explica en palabras situaciones, lugares, objetos o personas. Este discurso es habitual en la parte probatoria, en los atestados policiales o documentos notariales que requieren descripción; c) discurso expositivo: presenta hipótesis, presunciones o deducciones mediante explicaciones lógicas y sistemáticas. Se usa en los "fundamentos de derecho"4 de las sentencias, en los recursos y en los "preámbulos" o "exposición de motivos"5 de leyes o en la "doctrina jurídica"6; d) discurso persuasivo: trata de influir y convencer a través de elementos emotivos, connotativos, argumentativos o lúdicos a aquel que escucha o lee determinadas ideas o teorías. Se usa la adjetivación valorativa, adverbios y expresiones de opinión o conjunciones consecutivas; e) discurso exhortativo: trata de persuadir a alguien para que haga o no algo mediante el uso de razonamientos, apelaciones o ruegos. Normalmente, este discurso se halla en textos dirigidos a una instancia dotada de poder judicial; f) discurso dispositivo: expone un mandato u orden por parte de aquel que tiene autoridad para ello, por ejemplo, los jueces en las sentencias. Este tipo de discurso está caracterizado por el uso de imperativos y el futuro con valor prescriptivo; g) discurso declarativo: manifiesta la voluntad de la persona que emite el texto, oral o escrito; h) discurso prescriptivo: expresa las situaciones o circunstancias susceptibles de generar derechos u obligaciones. Es habitual el uso del futuro de indicativo con valor prescriptivo.

Este tipo de géneros discursivos, presentes en diversos tipos de textos jurídicos como leyes, sentencias, contratos, demandas o testamentos entre otros (Borja, 2000: 84 y ss.), están relacionados directamente con los tipos de macrofunciones propuestos por el MCER (2002: 123), por lo que los profesores de español jurídico deben asegurarse de que los alumnos comprenden las diferencias en la finalidad de cada uno de estos textos y que son capaces de producirlos. Adicionalmente, los alumnos deben entender que cada texto correspondiente a una macrofunción determinada tiene una organización textual propia que debe respetarse para que el mismo tenga el efecto deseado y siga con las pautas establecidas tanto en el ordenamiento jurídico español como en las prácticas habituales de la profesión.

«En los escritos administrativos o procesales de las partes, y en las resoluciones de las administraciones públicas, y de los jueces y tribunales o de los secretarios judiciales, relación clara y ordenada, habitualmente en párrafos separados y numerados, de los presupuestos fácticos en que se basan las pretensiones o las decisiones.» (“Diccionario panhispánico del español jurídico”, 2020).

«Una de las cuatro partes que constituyen la estructura formal de las sentencias, en la que en párrafos separados y numerados se contienen las razones y fundamentos legales del fallo, con expresión concreta de las normas jurídicas aplicables al caso.» ("Diccionario panhispánico del español jurídico", 2020).

«Parte expositiva o texto introductorio, carente de valor normativo, que antecede habitualmente al articulado de una norma jurídica. Recibe también el nombre de exposición de motivos.» (“Diccionario panhispánico del español jurídico”, 2020).

«Opinión sostenida en las obras de juristas de reconocido prestigio.» (“Diccionario panhispánico del español jurídico”, 2020). 


\subsubsection{Las prácticas profesionales}

Uno de los objetivos de la enseñanza de la lengua de especialidad es el aprendizaje de la "cultura profesional", es decir, de los comportamientos y actitudes profesionales ante situaciones cotidianas, así como de las normas de interacción y mediación ("Diccionario de términos clave en ELE", 2008). Para llevar al aula las prácticas profesionales, deben proponerse situaciones reales a través de las cuales se trabaje la competencia pragmática y los elementos socioculturales. El objetivo final de la enseñanza de la cultura profesional debe ser potenciar y desarrollar la competencia sociolingüística, es decir, «el conocimiento y las destrezas necesarias para abordar la dimensión social del uso de la lengua» (MCER, 2002: 116). A este respecto, Gómez de Enterría (2006: 53), citada en Rodríguez-Piñero y García (2009: 923), indica que la enseñanza de la lengua de especialidad debe llevarse a cabo «teniendo en cuenta los aspectos lingüísticos, pragmáticos y funcionales, es decir, dando cabida a contenidos gramaticales, discursivos, sociolingüísticos y socioculturales».

Mora (2017) pone de relieve una característica propia del español jurídico oral, las situaciones interaccionales ante las que los profesionales del derecho se encuentran. En función de los interlocutores, se pueden distinguir dos de estas situaciones: interacción entre profesionales e interacción entre profesional y no profesional. Dado que la conducta interaccional oral de los profesionales del derecho no se ajusta al nivel sociocultural de los ciudadanos, el alumnado debe adquirir destrezas y estrategias para moderar su discurso en función de su interlocutor (Mora, 2017). Por todo ello, es de especial relevancia mostrar y practicar con los alumnos diferentes situaciones interaccionales, comunicativas, que podrían darse en la vida profesional. Por ejemplo, dos situaciones reales sobre un mismo asunto en los que la lengua se debe ajustar podrían ser la reunión inicial con un cliente que expone sus preocupaciones legales a un abogado y la exposición del caso por parte del abogado que ha asistido a la reunión con el cliente a los socios del bufete.

\section{Propuesta didáctica de intervención}

\subsection{Presentación}

La presente propuesta didáctica tiene como objetivo llevar a la práctica los aspectos teóricos del español jurídico, tanto los lingüísticos como los relativos a la cultura profesional jurídica, a través del estudio de la adaptación de un caso real de la jurisprudencia penal española. Se propone una unidad didáctica en la que se acerca al alumno a la vida real de un abogado penalista y en se le dan herramientas y estrategias de aprendizaje para que este pueda desarrollar su autonomía como estudiante de español jurídico. Una de las herramientas propuestas es el "Diccionario panhispánico del español jurídico", en adelante "DPEJ", que recoge el lenguaje jurídico de la comunidad hispanoamericana y enlaza la entrada correspondiente con la legislación de los países pertenecientes a la Cumbre Judicial Iberoamericana7. Además de la autonomía del estudiante, esta herramienta también permite trabajar la interculturalidad del mundo jurídico hispanoamericano.

Además, en esta propuesta se incluyen textos reales, como por ejemplo extractos de leyes o modelos de textos jurídicos. Estos textos se van a aprovechar no solo para destacar los aspectos lingüísticos del español jurídico sino para potenciar la reflexión lingüística y cultural del mismo.

7 Andorra, Argentina, Bolivia, Brasil, Chile, Colombia, Costa Rica, Cuba, Ecuador, El Salvador, España, Guatemala, Honduras, México, Nicaragua, Panamá, Paraguay, Perú, Portugal, Puerto Rico, República Dominicana, Uruguay y Venezuela. 
Antes de ahondar en la propuesta, es imprescindible establecer que los contenidos de la misma están relacionados con la lengua de especialidad y no con la especialidad. La unidad didáctica está enfocada al trabajo de ciertas estructuras lingüísticas, léxico, tipología discursiva y cultura profesional jurídica y no al estudio del derecho procesal penal o del derecho penal español. Es por este motivo que no se va a realizar un estudio pormenorizado de todos los trámites, procedimientos y escritos que deberían llevarse a cabo en la práctica profesional en un caso similar al propuesto. En caso de pretender explicar el procedimiento en su totalidad esta propuesta aspiraría a enseñar derecho y no español jurídico. Es importante que los alumnos conozcan este matiz al inicio de la unidad didáctica.

Finalmente, el objetivo de esta propuesta didáctica es que los alumnos generen dos productos jurídicos finales, un escrito de calificaciones provisionales y una exposición oral de dicho escrito en sede judicial, que serán objeto de evaluación.

\subsubsection{Metodología}

Según Aguirre Beltrán (2004: 1123), la metodología en la enseñanza de lenguas de especialidad debe basarse en las actividades desarrolladas por los profesionales del campo concreto. En este sentido, algunos de los métodos de trabajo pertinentes en este caso son la simulación global, el enfoque por tareas, las presentaciones orales, los estudios de casos y las simulaciones (Aguirre, 2004: 1123-1125; Rodríguez-Piñero y García, 2009: 924; y "Diccionario de términos clave en ELE", 2008). Además de estas metodologías, es de especial relevancia el enfoque orientado a la acción, que aparece en el MCER (2002: 9) y está íntimamente relacionado con el enfoque por tareas.

Es conveniente destacar que la presente propuesta no se basa en una única metodología, sino que se elige aquella más adecuada según la actividad propuesta (Puren: 2004, 34). Las metodologías usadas en la presente propuesta son: el enfoque por tareas, el enfoque orientado a la acción y en la simulación. Cada una de estas metodologías tiene características distintas que pueden aprovecharse en favor del alumnado. Por un lado, el enfoque por tareas se basa en actividades de uso de la lengua e incentiva el aprendizaje mediante el uso real de la misma. Por otro lado, el enfoque orientado a la acción va un paso más allá y considera al alumno como un todo global, es decir, como un miembro de la sociedad que debe realizar tareas que superan lo meramente lingüístico. Estas tareas están relacionadas tanto con el uso de la lengua como con las circunstancias, el entorno y el campo de acción concreto en el que se desarrolla la comunicación. Finalmente, la simulación consiste en la presentación de una situación comunicativa real en la que los estudiantes deben saber usar la lengua de forma adecuada así como saberse desenvolver socialmente usando la misma en una situación planteada.

En consecuencia, el uso de las tres metodologías a lo largo de las actividades de la propuesta de intervención permiten que el alumno aprenda y ponga en práctica la lengua desde perspectivas diversas, desde el mero estudio de ciertas estructuras gramaticales, pasando por la adecuación del discurso en función del contexto planteado, hasta llegar a la simulación de una situación real en la que la actuación del estudiante debe ser adecuada tanto desde el punto de vista lingüístico como desde el punto de "agente social".

\subsection{Objetivos de la propuesta didáctica}

El objetivo general de esta propuesta es desarrollar una unidad didáctica que posibilite llevar al aula de español jurídico actividades que permitan introducir y trabajar las especificidades del español jurídico a la vez que se 
potencia la interculturalidad, la autonomía, la motivación y el desarrollo de las cuatro destrezas lingüísticas. En cambio, los objetivos específicos de la unidad didáctica son que los estudiantes analicen y aprendan el futuro de subjuntivo; analicen las situaciones comunicativas en función del contexto jurídico en el que se encuentren; desarrollen su capacidad de argumentación, convicción, desacreditación, descripción y narración a través de textos orales y escritos; desarrollar la autonomía de los estudiantes; trabajar la capacidad de síntesis; y, desarrolla la competencia comunicativa a través de la dramatización y la simulación de situaciones reales.

\subsection{Contexto}

El contexto en el que se plantea aplicar esta propuesta de intervención no es un contexto real, sino que es un contexto hipotético en el que sería ideal emplearla.

La propuesta se plantea para un grupo de 10 a 15 alumnos con un nivel $\mathrm{C} 1$ que estudian un curso de español jurídico impartido en una universidad extranjera europea, en la que se sigue un sistema jurídico continental. Los alumnos son estudiantes de derecho u otros estudios equivalentes al grado de derecho en España con conocimientos previos sobre la materia. Si los alumnos procedieran de otro sistema jurídico, como por ejemplo el sistema anglosajón, la propuesta debería modificarse o explicarse de un modo que se adaptara mejor a los conocimientos jurídicos previos del alumnado. El horario ideal sería de 3 horas a la semana divididas en dos sesiones de 1 hora y 30 minutos cada una de ellas.

\subsection{Actividades}

3.4.1. Actividad 1. ¿Qué te sugiere el "Derecho Penal”?

\begin{tabular}{l}
\hline "DERECHO PENAL" \\
\hline Descripción y desarrollo: \\
La unidad didáctica empieza con una lluvia de ideas, actividad que sirve de activación. El profesor \\
escribirá en la pizarra "Derecho Penal" e indicará a los alumnos que deben decir las palabras \\
relacionadas con el tema que les vengan a la cabeza. El profesor irá apuntando las palabras que \\
surjan en la pizarra. \\
Una vez acabada la lluvia de ideas, y con el fin de centrar el tema sobre el que se van a desarrollar \\
las siguientes actividades, un caso de asesinato, se realizará un mapa conceptual partiendo de la \\
palabra "delito", que muy probablemente habrá salido en el primer ejercicio. En caso de que esta \\
palabra no haya aparecido la propondrá el profesor. \\
Materiales: \\
• Pizarra. \\
Contenidos: \\
• Léxico jurídico genérico.
\end{tabular}

Tabla 1. Actividad 1. ¿Qué te sugiere el "Derecho Penal"?

\subsubsection{Actividad 2. El escenario del crimen}

\section{"EL ESCENARIO DEL CRIMEN"}

\section{Descripción y desarrollo:}

Al inicio de esta actividad se entregará a los alumnos una ficha de trabajo (Anexo I) en la que se plantearán preguntas relacionadas con léxico jurídico básico de común conocimiento. Se empezará 


\section{"EL ESCENARIO DEL CRIMEN"}

mostrando un vídeo ${ }^{8}$ en el que se resumen de manera objetiva los hechos del caso que se va a tratar. El vídeo se pondrá dos veces, la primera vez se espera que los alumnos se formen una idea general del caso y se les pedirá que no rellenen la ficha de trabajo. Antes de ver el vídeo por segunda vez, se leerán las preguntas de la ficha en voz alta para comprobar que los alumnos comprenden bien lo que se pide, así como el vocabulario. Una vez se hayan leído las preguntas se pondrá el vídeo de nuevo y se pedirá a los estudiantes que contesten las preguntas de comprensión. Esta actividad se realizará de forma individual, posteriormente se compararán las respuestas con un compañero y finalmente se corregirán en grupo.

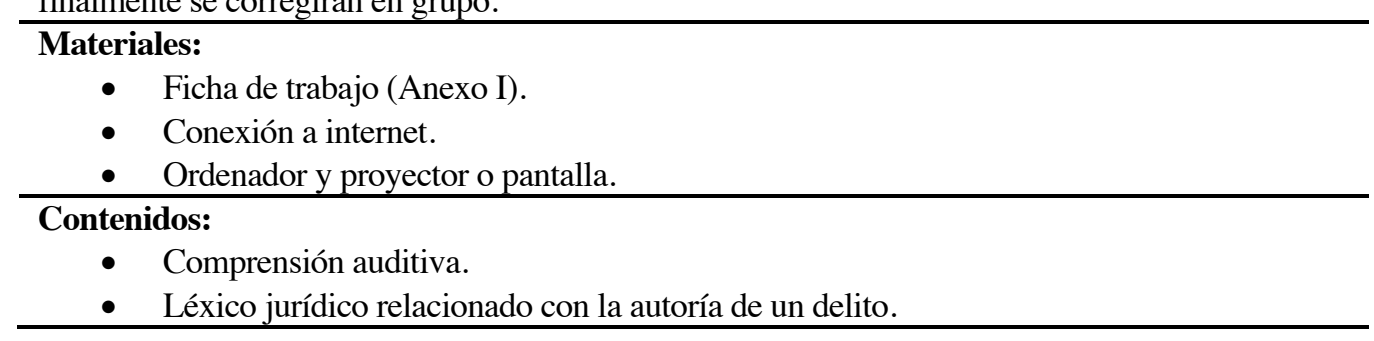

Tabla 2. Actividad 2. El escenario del crimen

\subsubsection{Actividad 3. ¿Qué ha pasado?}

\begin{tabular}{l}
\hline “QUÉ HA PASADO?” \\
\hline Descripción y desarrollo: \\
El profesor indicará a los alumnos que en esta actividad se van a simular las entrevistas que \\
mantienen los abogados con sus clientes y una conversación entre la Fiscalía y la policía. Se \\
dividirá el grupo-clase en tres grupos de entre tres y cinco alumnos, que se mantendrán hasta el \\
final de la unidad didáctica, y se les asignará un rol: Fiscalía, defensa de Rosa y defensa de Pedro. \\
Para llevar a cabo las simulaciones se entregará un documento a todos los grupos en el que se \\
detalla el contexto en el que se encuentran (Anexo II). Además, se pedirá a un alumno voluntario \\
para que interprete el papel de policía y a otros dos para que interpreten el papel de sospechosos. \\
Se les entregará un documento con la versión de los hechos que deben contar (Anexo III). \\
Se dará a los alumnos unos minutos para que puedan hablar con sus respectivos equipos sobre la \\
información que quieren recabar y a los voluntarios para leer la versión de los hechos que deben \\
contar. Posteriormente, cada uno de los equipos realizará la entrevista correspondiente ante todo el \\
grupo-clase. El profesor será un mero espectador que resolverá dudas. \\
\hline Materiales: \\
• Ficha relativa al contexto e instrucciones (Anexo II) \\
• Ficha relativa al discurso de los dos sospechosos e informe policial (Anexo III) \\
Contenidos: \\
• Expresión oral. \\
• Léxico jurídico apropiado en función del contexto en el que se encuentre el alumno. \\
• Trabajo de la competencia comunicativa. \\
• Comprensión lectora.
\end{tabular}

Tabla 3. Actividad 3. ¿Qué ha pasado?

8 https://www.youtube.com/watch?v=_8BAyS_tyRQ 


\subsubsection{Actividad 4. Hablemos de leyes}

\section{"HABLEMOS DE LEYES"}

\begin{tabular}{l}
\hline Descripción y desarrollo: \\
El profesor repartirá a los alumnos una ficha de trabajo (Anexo IV) en la que aparecen algunos \\
artículos extraídos del código penal y se plantearán algunas preguntas relativas a la gramática usada \\
en los mismos. En el primer ejercicio se pondrá de relieve el uso del futuro de subjuntivo en el \\
español jurídico y se resaltará el hecho de que en el español general este tiempo verbal ha caído en \\
desuso. Es esencial que los alumnos lo conozcan y lo comprendan debido a que en caso contrario \\
podrían encontrarse con problemas futuros en la consecución de parte de sus estudios de derecho \\
en España. Asimismo, los extractos de la ley presentados también resultarán de utilidad para hablar \\
sobre el léxico jurídico español. A este respecto, el profesor proporcionará recursos, herramientas \\
y estrategias para que el alumno, como aprendiente autónomo, pueda encontrar solución por sí \\
mismo a las dificultades léxicas ante las que se encuentre. Uno de estos recursos es el "Diccionario \\
panhispánico del español jurídico" de la RAE (https://dpej.rae.es/). Estas actividades se realizarán \\
de forma individual y se comentarán y corregirán en grupo posteriormente. \\
Para terminar, se leerá un artículo de la Ley Orgánica 5/1995, de 22 de mayo, del Tribunal del \\
Jurado y se propondrá un debate intercultural relativo a la institución del Tribunal del Jurado. El \\
objetivo es que los alumnos comparen esta figura de la legislación española con la de su país y den \\
su opinión sobre la misma. \\
\hline Materiales: \\
- Ficha de trabajo (Anexo IV). \\
- Conexión a internet. \\
\hline Contenidos: \\
- Aprendizaje autónomo del estudiante. \\
- Trabajo del futuro de subjuntivo. \\
- Expresión escrita. \\
- Expresión oral. \\
- Trabajo de la interculturalidad. \\
\hline
\end{tabular}

Tabla 4. Actividad 4. Hablemos de leyes

\subsubsection{Actividad 5. Empecemos con los escritos}

\begin{tabular}{l}
\hline "EMPECEMOS CON LOS ESCRITOS” \\
\hline Descripción y desarrollo: \\
Esta actividad está destinada a facilitar a los alumnos la redacción de los escritos de calificación \\
provisional y ocupará dos sesiones. Aquí el profesor deberá advertir que en clase los escritos de \\
calificación de todos los grupos se redactarán y entregarán simultáneamente. Sin embargo, en la \\
realidad la acusación o acusaciones presentarían el escrito de calificación en primer lugar, y \\
posteriormente este se remitiría a la defensa o defensas para que pudieran presentar sus escritos \\
teniendo en cuenta las acusaciones. \\
En la primera sesión el profesor repartirá la ficha de trabajo (Anexo V), se realizará el primer \\
ejercicio de la ficha individualmente y después se corregirá. Posteriormente, se hará el segundo \\
ejercicio en parejas y se pondrá en común. Para acabar, se realizarán los ejercicios restantes de \\
forma individual o en parejas y se corregirán entre todos. \\
En la segunda sesión, se indicará a los alumnos que deben agruparse en los grupos asignados y \\
empezar con la redacción del escrito de calificación provisional. Se entregará una ficha con la \\
legislación necesaria para resolver el caso (Anexo VI). Puesto que esta es una tarea laboriosa y en \\
la que es posible que los alumnos tengan dudas, se dedicará toda la sesión a preparar estos escritos. \\
Este escrito será una de las actividades que se evaluarán y deberá entregarse en la última sesión de \\
la unidad didáctica. \\
\hline Materiales: \\
• Ficha de trabajo (Anexo V)
\end{tabular}




\section{"EMPECEMOS CON LOS ESCRITOS"}

Contenidos:

- Ficha de legislación (Anexo VI)

- Trabajo de los géneros discursivos.

- Estructura de los textos jurídicos en general y del de calificación provisional en concreto.

- Comprensión lectora.

- Fomento del trabajo en grupo.

- Fomento del trabajo cooperativo entre todos los alumnos del grupo-clase.

Tabla 5. Actividad 5. Empecemos con los escritos

\subsubsection{Actividad 6. Con la venia señoría}

\section{"CON LA VENIA SEÑORÍA"}

\section{Descripción y desarrollo:}

Esta actividad, que ocupará dos sesiones, pretende proporcionar a los alumnos los conocimientos y estrategias necesarios para poder exponer oralmente el escrito de calificaciones provisionales. En la primera sesión se empezará repartiendo la ficha de trabajo correspondiente (Anexo VII). Se indicará a los alumnos que se va a ver una parte de un vídeo ${ }^{9}$ (49:56 a 60:00) de una simulación de la exposición de los argumentos finales en sede judicial. Antes se pedirá que lean las preguntas y que las contesten a medida que van viendo el vídeo. Finalmente, los alumnos se agruparán con sus equipos y empezarán a preparar la exposición oral de sus escritos. El profesor deberá recordar que todos los miembros del equipo deben participar en la exposición oral.

En la segunda sesión se procederá a la simulación de la exposición oral de las calificaciones provisionales en sede judicial. Finalmente, se dedicará el final de la sesión a las conclusiones finales y a resolver las dudas que puedan surgir. Además, se repartirá o enviará vía email la sentencia de la Audiencia Provincial de Barcelona 13/2020, de 14 de abril de 2020, que resuelve el caso tratado para que los alumnos que tengan interés en saber la resolución final del tribunal español puedan leerla.

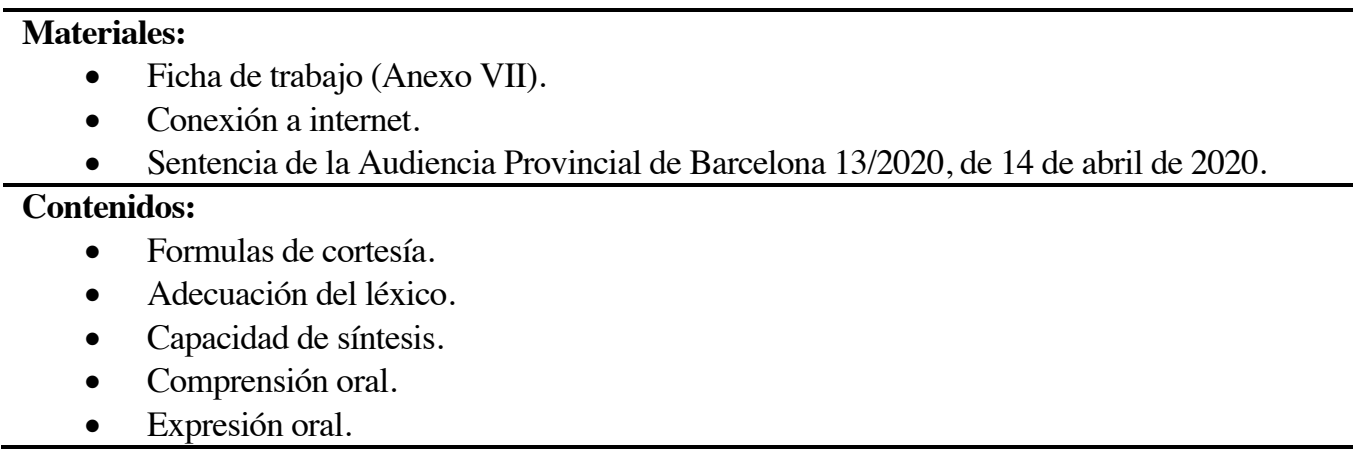

Tabla 4. Actividad 6. Con la venia señoría

\subsection{Evaluación}

La evaluación de la presente propuesta se va a desarrollar en dos partes. Por un lado, se va a evaluar la producción escrita, es decir, los escritos de calificación provisional de acusación y defensa (Anexo VIII). Por otro lado, se va a evaluar la producción oral, es decir, la simulación de la exposición del contenido de los escritos en sede judicial a través de una rúbrica creada tomando como referencia las rúbricas de evaluación de Buyse (2011: 194196) (Anexo IX).

$9 \quad \underline{h t t p s}: / / w w w . y o u t u b e . c o m / w a t c h ? v=p 2 e I F F z 4018 \& t=1105 \mathrm{~s}$ 


\section{Conclusiones}

Para acabar, en el presente artículo se ha tratado de hacer un recorrido a través de las lenguas de especialidad y de las características que estas comparten. Concretamente, se ha tratado el español jurídico y sus peculiaridades, tanto lingüísticas como culturales, desde un punto de vista teórico-práctico.

Desde el punto de vista teórico, algunos autores, como Gutiérrez (2010: 2) y Méndez y Gil del Moral (2019: 14), han indicado que el español jurídico no es un campo que goce de demasiada investigación. Sin embargo, se han mencionado diversos autores, como por ejemplo Gutiérrez (2007, 2010, 2011), Gómez de Enterría (2009), Calahorro (2015), García (2016), Bastidas (2016 y 2019), Mora (2017), Méndez y Gil del Moral (2019), Sabater (2019), entre muchos otros, que han dedicado sus investigaciones al campo del español de especialidad y al español jurídico. Gracias a estos autores se ha podido analizar qué se entiende por español de especialidad y en concreto español jurídico, así como las características de la gramática, el léxico y los géneros discursivos propios de este tipo de especialidad. Asimismo, también se ha puesto de relieve la importancia de la enseñanza de la cultura en el aula de ELE en general y de EFE en particular. Es precisamente gracias a la enseñanza de esta cultura, o "cultura profesional", que los alumnos podrán adquirir una buena competencia comunicativa que les permitirá adaptar los aspectos formales de la lengua a los diferentes contextos profesionales en los que se encuentren.

Para lograr que los alumnos lleguen a aprender y adquirir las características del español jurídico, se ha propuesto una unidad didáctica que gira alrededor de la adaptación de un caso real de la jurisprudencia española. Algunos aspectos que tienen una especial relevancia en la propuesta de intervención son el uso de textos reales, tanto orales como escritos, y la potenciación de los aspectos afectivos del aprendizaje a través de la estimulación del aprendizaje autónomo. Asimismo, respecto a la metodología usada para implementar la propuesta didáctica, se considera que no existe una única metodología aplicable. Por ello, después de analizar las características de algunas de las metodologías, se ha llegado a la conclusión de que resulta rentable aplicar tres metodologías diferentes: enfoque por tareas, enfoque orientado a la acción y simulación. La combinación de estas tres metodologías permite trabajar la lengua desde un punto de vista formal mediante el uso de textos reales de la misma, asimismo, permite considerar al estudiante como un todo global, es decir, un miembro de la sociedad que debe comunicarse usando la lengua en situaciones que superan lo meramente lingüístico. Finalmente, se brinda la oportunidad de aplicar lo aprendido en una situación comunicativa concreta en la que el estudiante debe saber no solo usar la lengua pero desenvolverse socialmente de una forma adecuada.

Por un lado, el uso de textos jurídicos reales, como por ejemplo los extractos del código penal, permiten que los alumnos adquieran los conocimientos lingüísticos de cada una de las situaciones comunicativas profesionales propuestas. A través del estudio de las leyes se acerca al estudiante de español jurídico a la realidad de los profesionales del derecho debido a que deben leer y analizar los mismos textos que usan diariamente los abogados y profesionales jurídicos en España. Asimismo, a través del análisis de un escrito de calificaciones provisionales se analiza la estructura que deben tener los textos jurídicos de este tipo para que sean válidos lingüísticamente y admisibles jurídicamente.

Por otro lado, la propuesta de intervención que se presenta en este trabajo potencia los factores afectivos del alumno, uno de los cuales es la motivación, aunque es cierto que los alumnos de EFE tienen una gran motivación per se (Ainciburu y Suñén, 2019: 41). Sin embargo, esta se trata de mantener y desarrollar a través de la presentación de un caso que ocupa toda la unidad didáctica. Se busca que los alumnos quieran saber más sobre 
el caso y se comprometan con las posiciones que deben defender a la vez que se trabajan los aspectos lingüísticos y culturales propios del español jurídico.

Por último, a través de la propuesta, se ha intentado promover la autonomía del estudiante mediante el ofrecimiento de recursos al mismo para que este se pueda hacer cargo de parte de su propio aprendizaje.

\section{Declaration of conflicting interests}

The author(s) declared no potential conflicts of interest with respect to the research, authorship, and/or publication of this article.

\section{Funding}

The author(s) received no financial support for the research, authorship, and/or publication of this article.

\section{Sobre los autores}

Esther Sanz i Vilar, nacida en Barcelona en mayo de 1995, estudió el grado en derecho en la Universidad Pompeu Fabra, el Máster de Acceso a la Abogacía y se hizo abogada en 2019. Después de trabajar como abogada durante 2 años, decidió hacer un cambio de rumbo profesional y estudiar el Máster en Enseñanza del Español como lengua extranjera. A raíz de este máster tuvo la oportunidad de colaborar con la Universidad de Turín impartiendo un curso de conversación de español. Actualmente es profesora de español y de inglés en academias privadas en Turín.

Santiago Sevilla-Vallejo. Profesor Ayudante Doctor en la Universidad de Salamanca. Ha sido secretario de la Federación de Asociaciones de Profesores de Español y es director de la revista Cálamo FASPE. Dirige el Congreso Internacional Las Desconocidas. Estudios sobre la construcción de la identidad femenina en la literatura, que forma parte del grupo de investigación Escritoras y personajes femeninos en la literatura (Universidad de Salamanca). Ha sido finalista del III Premio Educa Abanca. Mejor Docente de España, en la categoría Universidad; y del premio de investigación de la Primera edición del Congreso Internacional de Escritores y Artistas; y del International Research Awards on Psychiatry and Mental Health (2021) en la categoría Research award. Su línea de investigación se centra en el estudio de la narrativa para establecer la relación entre la elaboración del discurso y la construcción de la identidad, particularmente de la identidad de género.

\section{Bibliografía}

Abogacía Española. (2020). La RAE presenta la edición en línea del Diccionario panhispánico del español jurídico: todas las legislaciones en un clic. Recuperado de https://www.abogacia.es/actualidad/noticias/la-rae-presenta-la-edicion-en-linea-deldiccionario-panhispanico-del-espanol-juridico/ 
Ainciburu, M. C. \& Suñén, M. C. (2019). El reto de programar un curso de Español para Fines Específicos en el marco de la enseñanza superior. En L. Magnacco, I. Pérez, J. Schnitzer y R. Veiga (Eds.), JEFE-Vi I: Contribuciones a las Primeras Jornadas de Español para Fines Específicos de Viena (pp. 33-47). Viena: Ministerio de Educación y Formación Profesional/Secretaría General Técnica.

Aguirre, B. (2012). Aprendizaje y enseñanza de español con fines específicos. Madrid: SGEL.

Alcaraz, E. \& Huges, B. (2002). El español jurídico. Barcelona: Ariel.

Bastidas, E. (2016). Las colocaciones en el español jurídico y su tratamiento en el aula de español para extranjeros (Tesis doctoral). Universitat de València, Valencia.

Bastidas, E. (2019). El uso de mapas mentales en la enseñanza-aprendizaje de las colocaciones: aplicación didáctica en el español jurídico. Quaderns digitals: Revista de Nuevas Tecnologías y Sociedad, (88), 182-210.

Borja, A. (2000). El texto jurídico inglés y su traducción al español. Barcelona: Ariel.

Buyse, K. (2011). Criterios y plantillas para la evaluación oral del español para fines específicos. En A. Escofet, K. Jauregi, B. de Jonge, L. Vangehuchten (Eds.), El español de las profesiones. Artículos seleccionados del IV Congreso Internacional de Español para Fines Específicos (pp. 187-199). Ámsterdam: Ministerio de Educación, Cultura y Deportes/Secretaría Técnica.

Calahorro, E. M. (2015). La enseñanza de español para fines específicos: el español jurídico (Tesis doctoral). Universidad de Málaga, Málaga.

Cumbre Judicial Iberoamericana. (2000-2017). Recuperado de http://www.cumbrejudicial.org/

Europa Press. (2020). Concluye la primera jornada del juicio del crimen de la Guardia Urbana. Recuperado de https://www.youtube.com/watch?v=8BAyS tyRQ.

García, A. \& Massaguer, L. (2011). La asignatura de Cultura en las aulas de E/LE de la universidad: Propuestas didácticas y actividades. Didáctica y materiales en el aula de E/LE en China. Conferencia llevada a cabo en IV Jornadas de Formación de Profesores de Español como Lengua Extranjera en China. Consejería de Educación de la Embajada de España en China, Instituto Cervantes de Pekín y SinoELE, Pekín.

García, M. (2016). Lenguas de especialidad y certificación lingüística. En E. Balmaseda, F. García y M. Martínez (Eds.), Panhispanismo y variedades en la enseñanza del español L2-LE (pp. 37-48). Logroño: Asociación para la Enseñanza del Español como Lengua Extranjera y Fundación San Millán de la Cogolla.

Gómez de Enterría, J. (2009). El lugar que ocupan las lenguas de especialidad en la enseñanza y aprendizaje del español como lengua extranjera. En A. Vera e I. Martínez (Eds.), El español en contextos específicos: Enseñanza e investigación. XX Congreso Internacional de la Asociación para la Enseñanza del Español como Lengua Extranjera (ASELE) (pp. 41-64). Comillas: Fundación Comillas.

Gutiérrez, J. M. (2010). El español jurídico: propuesta didáctica orientada a la acción como base para un curso. MarcoELE revista didáctica de español como lengua extranjera, (11), 1-24.

Gutiérrez, J. M. (2011). El español jurídico: Discurso profesional y académico. En el español de las profesiones. En A. Escofet, K. Jauregi, B. de Jonge, L. Vangehuchten (Eds.), El español de las profesiones. Artículos seleccionados del IV Congreso Internacional de Español para Fines Específicos (pp. 150-166). Ámsterdam: Ministerio de Educación, Cultura y Deportes/Secretaría Técnica.

Instituto Cervantes (2002). Marco común europeo de referencia para las lenguas: aprendizaje, enseñanza, evaluación. Madrid.

Instituto Cervantes (2008). Diccionario de términos clave en ELE. Recuperado de https://cvc.cervantes.es/Ensenanza/biblioteca ele/diccio ele/default.htm

Instituto Cervantes. (2012). Las competencias clave del profesorado de lenguas segundas y extranjeras. Recuperado de https://cvc.cervantes.es/ensenanza/biblioteca ele/competencias/default.htm

Méndez, M. C. y Gil del Moral, A. M. (2019). Introducción a la enseñanza de español con fines específicos. En G. Lima y G. Eres (Org.), Enseñanza de español con fines específicos: el caso de la carrera de turismo. Teoría y práctica (pp. 14-33). Madrid: Ministerio de Educación y Formación Profesional/Secretaría General Técnica.

Miquel, L. y Sans, N. (2004). El componente cultural: un ingrediente más en las clases de lengua. Red ELE revista electrónica de didáctica / español lengua extranjera, (0). 
Mora, M. A. (2017). Otrosí digo: La variación gramatical en el español jurídico para extranjeros. En L. Magnacco, I. Pérez, J. Schnitzer y R. Veiga (Eds.), JEFE-Vi I: Contribuciones a las Primeras Jornadas de Español para Fines Especificos de Viena (pp. 99-118). Viena: Ministerio de Educación y Formación Profesional/Secretaría General Técnica.

Pastor, S. (2010). Enseñanza de español con fines profesionales y académicos y aprendizaje por contenidos en contexto universitario. Testi e linguaggi (Università di Salerno), (4), 71-88.

Puren, C. (2004). Del enfoque por tareas a la perspectiva co-accional. Porta Linguarum, (1), 31-36.

Rodríguez-Piñero, A. I. y García, M. (2009). Lenguas de especialidad y lenguas para fines específicos: precisiones terminológicas y conceptuales e implicaciones didácticas. En A. Vera e I. Martínez (Eds.), El español en contextos específicos: Enseñanza e investigación. XX Congreso Internacional de la Asociación para la Enseñanza del Español como Lengua Extranjera (ASELE) (pp. 907-932). Comillas: Fundación Comillas.

Real Academia Española. (2020). Diccionario Panhispánico Del Español Jurídico. Recuperado de https://www.rae.es/obrasacademicas/diccionarios/diccionario-panhispanico-del-espanol-juridico

Real Academia Española. (2020). La RAE presenta la edición en línea del Diccionario panhispánico del español jurídico. Recuperado de https://www.rae.es/noticias/la-rae-presenta-la-edicion-en-linea-del-diccionario-panhispanico-del-espanol-juridico

Sabater, M. L. (2019). La docencia de Español para Fines Específicos, un marco idóneo para la investigación del profesor. En L. Magnacco, I. Pérez, J. Schnitzer y R. Veiga (Eds.), JEFE-Vi I: Contribuciones a las Primeras Jornadas de Español para Fines Específicos de Viena (pp. 18-31). Viena: Ministerio de Educación y Formación Profesional/Secretaría General Técnica.

Tong, X. (2013). Los estudios culturales en el aula de ELE: reflexiones y prácticas. En El enfoque intercultural en el aula de ELE en China. Conferencia llevada a cabo en las VI Jornadas de Formación de Profesores de ELE en China, Pekín.

Universidadurjc. (2017). Máster en abogacía: Juicio - $\quad$ Penal. Recuperado de https://www.youtube.com/watch?v=p2eIFFz4018\&t=1105s

Vilches, F. y Sarmiento, R. (2016). Lenguaje jurídico-administrativo. Una lengua de especialidad. Madrid: Dykinson.

Williams, R. (1987). Keywords. A vocabulary of culture and society. Londres: Fontana.

\section{Legislación y jurisprudencia}

España. Ley Orgánica 5/1995, de 22 de mayo, del Tribunal del Jurado. Boletín Oficial del Estado, 23 de mayo de 1995 , núm. 122.

España. Ley Orgánica 10/1995, de 23 de noviembre, del Código Penal. Boletín Oficial del Estado, 24 de noviembre de 1995, núm. 281.

Audiencia provincial de Barcelona (Tribunal del Jurado, Sección 100). Sentencia núm. 13/2020, de 14 de abril de 2020. 


\section{Anexo I}

\section{EL ESCENARIO DEL CRIMEN}

1. Mira el vídeo ${ }^{10}$ y completa la tabla siguiente:

\begin{tabular}{l|l|l|l|l}
\hline Sospechosos & Víctima & Acusación & $\begin{array}{c}\text { Lugar de } \\
\text { celebración del } \\
\text { juicio }\end{array}$ & Años de cárcel \\
\hline & & & & \\
& & & & \\
\hline
\end{tabular}

2. ¿Qué relación tenía la víctima con uno de los sospechosos?

3. Identifica las partes de este caso e indica si forman parte de la acusación o la defensa: Acusación:

Defensa:

\section{Anexo II}

\section{¿QUÉ HA PASADO?}

Agrúpate con el equipo que te ha tocado y discutid qué preguntas haríais a la parte contraria. A continuación se indica el contexto en el que se encuentra cada una de las partes:

1. Fiscalía: os entrevistáis con el cuerpo policial encargado de la investigación y queréis saber los resultados del atestado policial.

2. Defensa de Rosa: vuestra clienta Rosa ha sido detenida y está en las dependencias policiales esperando entrevistarse con su abogado. Como abogados de la sospechosa acudís donde se encuentra vuestra clienta para que os cuente qué ha sucedido.

3. Defensa de Albert: vuestro cliente Albert ha sido detenido y está en las dependencias policiales esperando entrevistarse con su abogado. Como abogados del sospechoso acudís donde se encuentra vuestro cliente para que os cuente qué ha sucedido.

\footnotetext{
$10 \quad$ https://www.youtube.com/watch?v=_8BAyS_tyRQ

Revista de Lenguas para Fines Específicos 27.1 ISSN : 2340-8561
} 


\section{Anexo III}

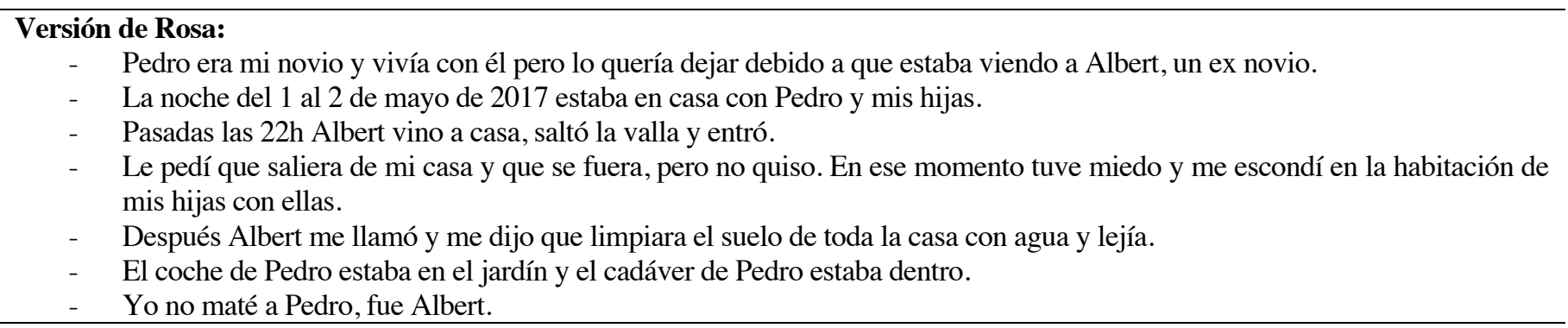

\section{Versión de Albert:}

- $\quad$ Rosa es mi ex novia y llevo un tiempo viéndola de nuevo.

- Pedro era el chico con el que Rosa mantenía una relación, vivían juntos pero lo quería dejar porque era una molestia para nuestra relación.

- $\quad$ La noche del 1 al 2 de mayo de 2017 Rosa me llamó y me pidió que saltara la valla de su casa para ir a su encuentro.

- Cuando salté la valla me encontré con el coche de Pedro en el jardín. Su cadáver estaba en el interior.

- $\quad$ No quise saber nada del asunto y me fui a mi casa.

- $\quad$ Yo no maté a Pedro, fue Rosa.

\section{HECHOS RESULTANTES DE LA INVESTIGACIÓN:}

En 2012 Rosa mantenía dos relaciones amorosas simultáneamente, una con Pedro y otra con Albert. Los tres implicados trabajaban juntos como policías en una comisaría cerca de Barcelona.

En 2016 la relación entre Rosa y Pedro se intensificó, hasta tal punto que se fueron a vivir juntos.

Más adelante, en 2017 Albert se enteró de la relación que Rosa mantenía con Pedro y el primero le contó a Pedro que Rosa también había empezado una relación con él. Este hecho provoca enfrentamientos entre la pareja (Rosa y Pedro), y grandes hostilidades entre Albert y Pedro.

En marzo o abril de 2017 hubo un acercamiento entre Rosa y Albert. En este punto Pedro resultaba un obstáculo para su relación debido a la hostilidad que este tenía con Albert, y por otro, la desconfianza creciente que sentía hacia Rosa. Es por ello que Rosa y Albert planearon el asesinato de Pedro.

La madrugada del 1 al 2 de mayo de 2017 fue la noche del asesinato. Rosa y Pedro pasaron la tarde juntos y después regresaron a la casa que compartían. Una vez en casa, Rosa llamó a Albert y hablaron durante 4 minutos, es probable que fuera en ese momento cuando decidieron llevar a cabo el crimen. Más tarde esa misma madrugada Albert fue a casa de Rosa y Pedro.

El día 4 de mayo del 2017 se encuentra en una carretera un coche calcinado. Entre los restos se encuentra el cadáver de Pedro, en tan mal estado que no se puede identificar la causa de la muerte. Pedro había sido operado de la pierna recientemente y se le implantó una prótesis gracias a la cual se puedo identificar su cadáver.

La investigación llevada a cabo revela que probablemente Rosa y Albert durmieron a Pedro con los calmantes que este tomaba para el dolor de pierna derivado de la operación, y que no se encontraron en la casa, lo mataron y después quemaron el coche con el cuerpo de la víctima dentro. 


\section{Anexo IV}

\section{HABLEMOS DE LEYES}

\section{Lee los siguientes artículos extraídos del código penal (CP) español y contesta a las preguntas}

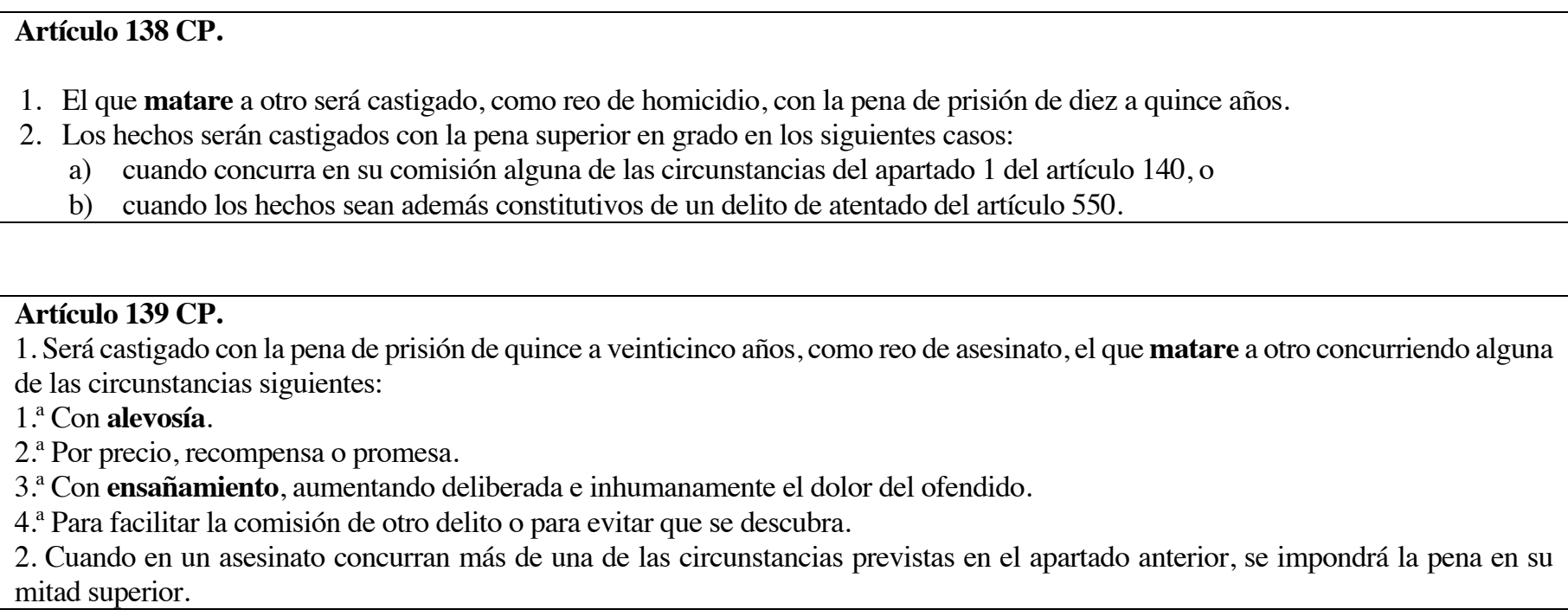

\section{a. ¿A qué tiempo verbal corresponde "matare"?}

b. ¿Qué te sugiere este tiempo verbal? ¿Qué crees que expresa?

c. Reescribe los dos artículos utilizando tiempos verbales más comunes en español.

2. Fíjate en el art. 139.1.1. CP. ¿Qué significa alevosía? ¿Y enseñamiento? Utiliza el Diccionario panhispánico del español jurídico de la RAE (https://dpej.rae.es/) y después explica el término con tus palabras.

3. Ahora fíjate en este artículo extraído de la Ley Orgánica 5/1995, de 22 de mayo, del Tribunal del Jurado:

\section{Artículo 1. Competencia del Tribunal del Jurado.}

1. El Tribunal del Jurado, como institución para la participación de los ciudadanos en la Administración de Justicia, tendrá competencia para el enjuiciamiento de los delitos atribuidos a su conocimiento y fallo por esta u otra Ley respecto de los contenidos en las siguientes rúbricas:

a) Delitos contra las personas.

b) Delitos cometidos por los funcionarios públicos en el ejercicio de sus cargos.

c) Delitos contra el honor.

d) Delitos contra la libertad y la seguridad.

2. Dentro del ámbito de enjuiciamiento previsto en el apartado anterior, el Tribunal del Jurado será competente para el conocimiento y fallo de las causas por los delitos tipificados en los siguientes preceptos del Código Penal:
a) Del homicidio (artículos 138 a 140).
b) De las amenazas (artículo 169.1. ${ }^{\circ}$ ).
c) De la omisión del deber de socorro (artículos 195 y 196).
d) Del allanamiento de morada (artículos 202 y 204).
e) De la infidelidad en la custodia de documentos (artículos 413 a 415).
f) Del cohecho (artículos 419 a 426).
g) Del tráfico de influencias (artículos 428 a 430). 
h) De la malversación de caudales públicos (artículos 432 a 434).

i) De los fraudes y exacciones ilegales (artículos 436 a 438)

j) De las negociaciones prohibidas a funcionarios (artículos 439 y 440).

k) De la infidelidad en la custodia de presos (artículo 471).

3. El juicio del Jurado se celebrará sólo en el ámbito de la Audiencia Provincial y, en su caso, de los Tribunales que correspondan por razón del aforamiento del acusado. En todo caso quedan excluidos de la competencia del Jurado, los delitos cuyo enjuiciamiento venga atribuido a la Audiencia Nacional.
a. ¿Qué es el Tribunal del Jurado?
b. ¿En tu país existe esta institución?
c. ¿Estás a favor o en contra de que los delitos mencionados en el artículo anterior se juzguen por el Tribunal del Jurado? ¿Por qué?

\section{Anexo V}

\section{EMPECEMOS CON LOS ESCRITOS}

1. Como sabes, los textos en general tienen una estructura determinada y lo mismo sucede con los textos jurídicos. Cada una de las partes de los textos jurídicos cumple con una función. Relaciona las funciones de la columna de la izquierda con las definiciones de la columna de la derecha.

\begin{tabular}{l}
\hline 1. Discurso narrativo \\
\hline 2. Discurso descriptivo \\
\hline 3. Discurso expositivo \\
\hline 4. Discurso persuasivo \\
\hline 5. Discurso exhortativo \\
\hline 6. Discurso dispositivo \\
\hline 7. Discurso declarativo \\
\hline 8. Discurso prescriptivo
\end{tabular}

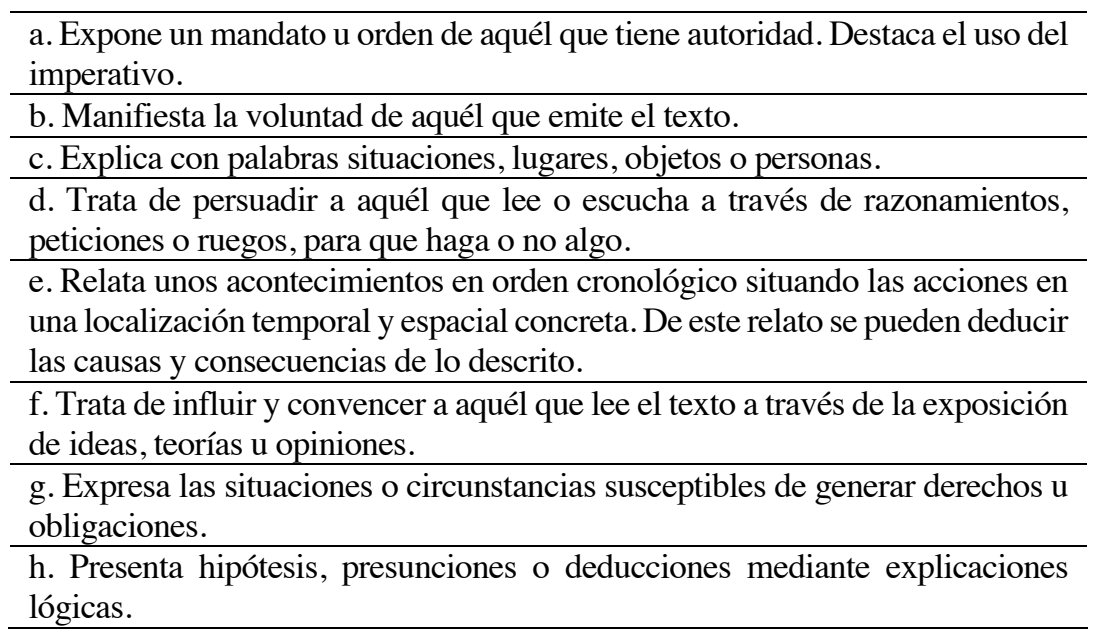

2. Ahora fíjate en el ejemplo de escrito de calificaciones provisionales de la defensa que se presenta a continuación. Indica las partes de las que se compone el texto y la función que cumple cada una de ellas.

\section{A LA SALA DE LA AUDIENCIA PROVINCIAL DE BARCELONA}

Doña A. M., Procuradora de los Tribunales, en nombre y representación de Don E. P., con domicilio en Barcelona y provisto de número de Documento Nacional de Identidad (DNI) 00000000X, tal como consta en el sumario número X procedente del Juzgado de Instrucción $\mathrm{n}^{\circ} \mathrm{X}$ de Barcelona, en aplicación del art. 652 LECrim, formulo escrito de defensa, en base a las siguientes:

\section{CONCLUSIONES PROVISIONALES}

\section{HECHOS}


1.- El 5 de noviembre de 2018 la Inspección de Trabajo de Barcelona realizó una inspección del régimen laboral de los trabajadores en el restaurante sito en la calle X de Barcelona. Dicha inspección estaba motivada por una denuncia interpuesta en la Inspección de Trabajo y de la Seguridad Social de Barcelona.

2.- Tras las comprobaciones llevadas a cabo por la Subinspectora encargada de la inspección, se comprobó que el cocinero del restaurante no cumplía con los requisitos legales para residir ni trabajar en España, por lo que se trasladó dicha información al cuerpo policial correspondiente para iniciar un expediente de expulsión por infracción de la Ley de Extranjería.

3.- A las 17:05 horas del 15 de enero de 2019 E. P., titular del mencionado restaurante, fue detenido para proceder a su interrogatorio, siendo puesto en libertad a las 19:45 horas de ese mismo día.

4.- El día 8 de abril del 2019 se dictó auto de incoación y trámite por el juzgado de Instrucción no X de Barcelona para el inicio de diligencias previas para la comprobación de un posible delito contra los derechos de los trabajadores, siendo nuestro representado, E. P., uno de los investigados.

5.- El cocinero del local declaró en condición de perjudicado, reconociendo en la declaración que llevaba en España cinco años sin permiso de residencia ni de trabajo. Además, declaró que trabajaba en el restaurante objeto de la inspección sin contrato y sin estar dado de alta en la Seguridad Social.

6.- Nuestro cliente declaró, en calidad de acusado, que había contratado al cocinero mediante un contrato verbal y era cierto que no estaba dado de alta en la Seguridad Social debido a que este le indicó que debía arreglar los documentos relativos a la residencia.

\section{CALIFICACIÓN LEGAL}

1.- La acusación indica que los hechos constituyen un delito contra los derechos de los trabajadores del art. 312.2. CP.

2.- Se considera que los hechos antes descritos no son constitutivos del delito del que se acusa a nuestro cliente debido a que no se dan los elementos del tipo. En primer lugar, no medió engaño en las condiciones de trabajo que se propusieron al cocinero debido a que estas se pactaron, aunque de forma oral, cosa que dificulta la prueba, pero no implica la inexistencia de dichos pactos. La prueba corresponde a la parte acusadora debido a que nuestro cliente está amparado por el derecho a la presunción de inocencia recogido en el art. 24.2. CE.

3.- Asimismo, el segundo elemento del tipo no se da debido a que no se aprecia que las condiciones del trabajador perjudicaran, suprimieran o restringieran sus derechos.

\section{AUTORÍA Y PARTICIPACIÓN}

De los anteriores hechos se considera que nuestro cliente no es autor del delito tipificado en el art. 312.2. CP.

\section{CIRCUNSTANCIAS MODIFICATIVAS}

No apreciamos hechos constitutivos de circunstancias atenuantes o agravantes, o eximentes de responsabilidad penal.

\section{V.PENALIDAD}

No procede imponer pena alguna, por lo que debe acordarse la libre absolución de nuestro cliente.

OTROSÍ PRIMERO.- MEDIOS DE PRUEBA de que intenta valerse esta parte para el acto del juicio en virtud del art. 784.2. LECrim:

1.. - Interrogatorio del cocinero para que conteste las preguntas que esta parte considere oportunas.

2. - - Testifical de los siguientes testigos:

- Sr. A, con DNI 00000000A, y domicilio en Calle A, Barcelona.

- Sra. B, con DNI 00000000B, y domicilio en Calle B, Barcelona.

Por lo expuesto,

SUPLICO AL JUZGADO que tenga por presentado este escrito y por evacuado el trámite de calificación provisional, interesando que se admitan las pruebas propuestas para el acto del juicio y que se ordene lo necesario para su práctica.

\section{En el escrito de calificaciones provisionales que se acaba de mostrar aparecen expresiones propias del escrito de defensa. Piensa con tu grupo expresiones que podría utilizar la acusación y ponlas en común con toda la clase.}

I. HECHOS:

II. CALIFICACIÓN LEGAL:

III. AUTORÍA Y PARTICIPACIÓN:

IV. CIRCUNSTANCIAS MODIFICATIVAS:

V. PENALIDAD: 
4. Como bien sabrás, una de las características del español jurídico son sus particularidades gramaticales. Busca en el texto uno o más ejemplos de las siguientes características gramaticales del español jurídico:

a. Sintaxis compleja: uso de oraciones largas en las que en ocasiones se rompe la sucesión natural de las oraciones.

b. Uso de formas no personales.

c. Uso de la voz pasiva.

d. Uso de perífrasis verbales de obligación y/o posibilidad.

e. Uso de siglas.

5. ¿Qué crees que significan las siglas que aparecen en el escrito?

- CP:

- LECrim:

- CE:

\section{Anexo VI}

\section{LEGISLACIÓN}

\section{Artículo 20. Eximente}

Están exentos de responsabilidad criminal:

$1 .{ }^{\circ}$ El que al tiempo de cometer la infracción penal, a causa de cualquier anomalía o alteración psíquica, no pueda comprender la ilicitud del hecho o actuar conforme a esa comprensión.

El trastorno mental transitorio no eximirá de pena cuando hubiese sido provocado por el sujeto con el propósito de cometer el delito o hubiera previsto o debido prever su comisión.

$2{ }^{\circ}$ El que al tiempo de cometer la infracción penal se halle en estado de intoxicación plena por el consumo de bebidas alcohólicas, drogas tóxicas, estupefacientes, sustancias psicotrópicas u otras que produzcan efectos análogos, siempre que no haya sido buscado con el propósito de cometerla o no se hubiese previsto o debido prever su comisión, o se halle bajo la influencia de un síndrome de abstinencia, a causa de su dependencia de tales sustancias, que le impida comprender la ilicitud del hecho o actuar conforme a esa comprensión. 
3. ${ }^{\circ} \mathrm{El}$ que, por sufrir alteraciones en la percepción desde el nacimiento o desde la infancia, tenga alterada gravemente la conciencia de la realidad.

4. ${ }^{\circ}$ El que obre en defensa de la persona o derechos propios o ajenos, siempre que concurran los requisitos siguientes:

Primero. Agresión ilegítima. En caso de defensa de los bienes se reputará agresión ilegítima el ataque a los mismos que constituya delito y los ponga en grave peligro de deterioro o pérdida inminentes. En caso de defensa de la morada o sus dependencias, se reputará agresión ilegítima la entrada indebida en aquélla o éstas.

Segundo. Necesidad racional del medio empleado para impedirla o repelerla.

Tercero. Falta de provocación suficiente por parte del defensor.

$5 .^{\circ} \mathrm{El}$ que, en estado de necesidad, para evitar un mal propio o ajeno lesione un bien jurídico de otra persona o infrinja un deber, siempre que concurran los siguientes requisitos:

Primero. Que el mal causado no sea mayor que el que se trate de evitar.

Segundo. Que la situación de necesidad no haya sido provocada intencionadamente por el sujeto.

Tercero. Que el necesitado no tenga, por su oficio o cargo, obligación de sacrificarse.

6. ${ }^{\circ}$ El que obre impulsado por miedo insuperable.

7..$^{\circ}$ El que obre en cumplimiento de un deber o en el ejercicio legítimo de un derecho, oficio o cargo.

En los supuestos de los tres primeros números se aplicarán, en su caso, las medidas de seguridad previstas en este Código.

\begin{abstract}
Artículo 23. Agravante
Es circunstancia que puede atenuar o agravar la responsabilidad, según la naturaleza, los motivos y los efectos del delito, ser o haber sido el agraviado cónyuge o persona que esté o haya estado ligada de forma estable por análoga relación de afectividad, o ser ascendiente, descendiente o hermano por naturaleza o adopción del ofensor o de su cónyuge o conviviente.
\end{abstract}
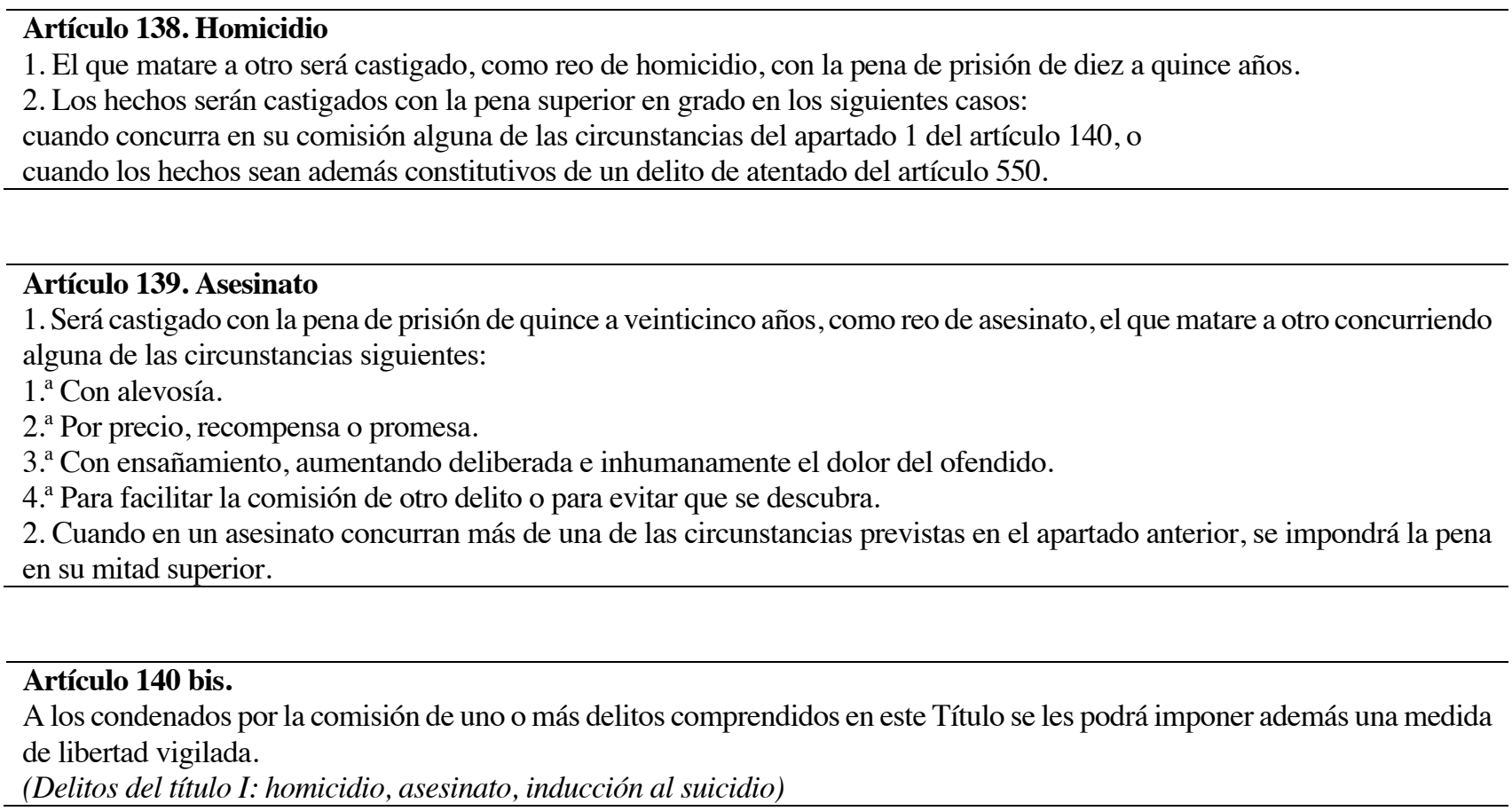

\begin{abstract}
Artículo 451. Encubrimiento
Será castigado con la pena de prisión de seis meses a tres años el que, con conocimiento de la comisión de un delito y sin haber intervenido en el mismo como autor o cómplice, interviniere con posterioridad a su ejecución, de alguno de los modos siguientes: 1. Auxiliando a los autores o cómplices para que se beneficien del provecho, producto o precio del delito, sin ánimo de lucro propio. 2. ${ }^{\circ}$ Ocultando, alterando o inutilizando el cuerpo, los efectos o los instrumentos de un delito, para impedir su descubrimiento.

3. ${ }^{\circ}$ Ayudando a los presuntos responsables de un delito a eludir la investigación de la autoridad o de sus agentes, o a sustraerse a su busca o captura, siempre que concurra alguna de las circunstancias siguientes:

a) Que el hecho encubierto sea constitutivo de traición, homicidio del Rey o de la Reina o de cualquiera de sus ascendientes o descendientes, de la Reina consorte o del consorte de la Reina, del Regente o de algún miembro de la Regencia, o del Príncipe o de la
\end{abstract}


Princesa de Asturias, genocidio, delito de lesa humanidad, delito contra las personas y bienes protegidos en caso de conflicto armado, rebelión, terrorismo, homicidio, piratería, trata de seres humanos o tráfico ilegal de órganos.

b) Que el favorecedor haya obrado con abuso de funciones públicas. En este caso se impondrá, además de la pena de privación de libertad, la de inhabilitación especial para empleo o cargo público por tiempo de dos a cuatro años si el delito encubierto fuere menos grave, y la de inhabilitación absoluta por tiempo de seis a doce años si aquél fuera grave.

\section{Anexo VII}

\section{CON LA VENIA SEÑORÍA}

1. Los juicios son actos procesales muy formales en los que se deben respetar ciertas normas de cortesía. Mira el final del vídeo ${ }^{11}$ y responde a las siguientes preguntas relativas a la formalidad del acto del juicio y al contenido de la exposición de los abogados:

a. ¿Qué dicen los abogados antes de hablar y de dirigirse al juez?

b. ¿Qué nombre le dan los abogados al juez?

c. ¿Qué parte se sienta a la derecha del juez? ¿Y a la izquierda?

d. ¿Se relacionan los abogados entre sí?

e. ¿A qué hacen referencia los abogados durante su exposición?

2. Agrúpate con tu equipo y preparad la exposición oral de vuestros escritos de calificaciones provisionales. Recuerda usar las formalidades que has visto en el vídeo anterior, son muy importantes. Asimismo, no olvides exponer el contenido del escrito de forma natural y resumida, no se trata de leer el escrito. 


\section{Anexo VIII}

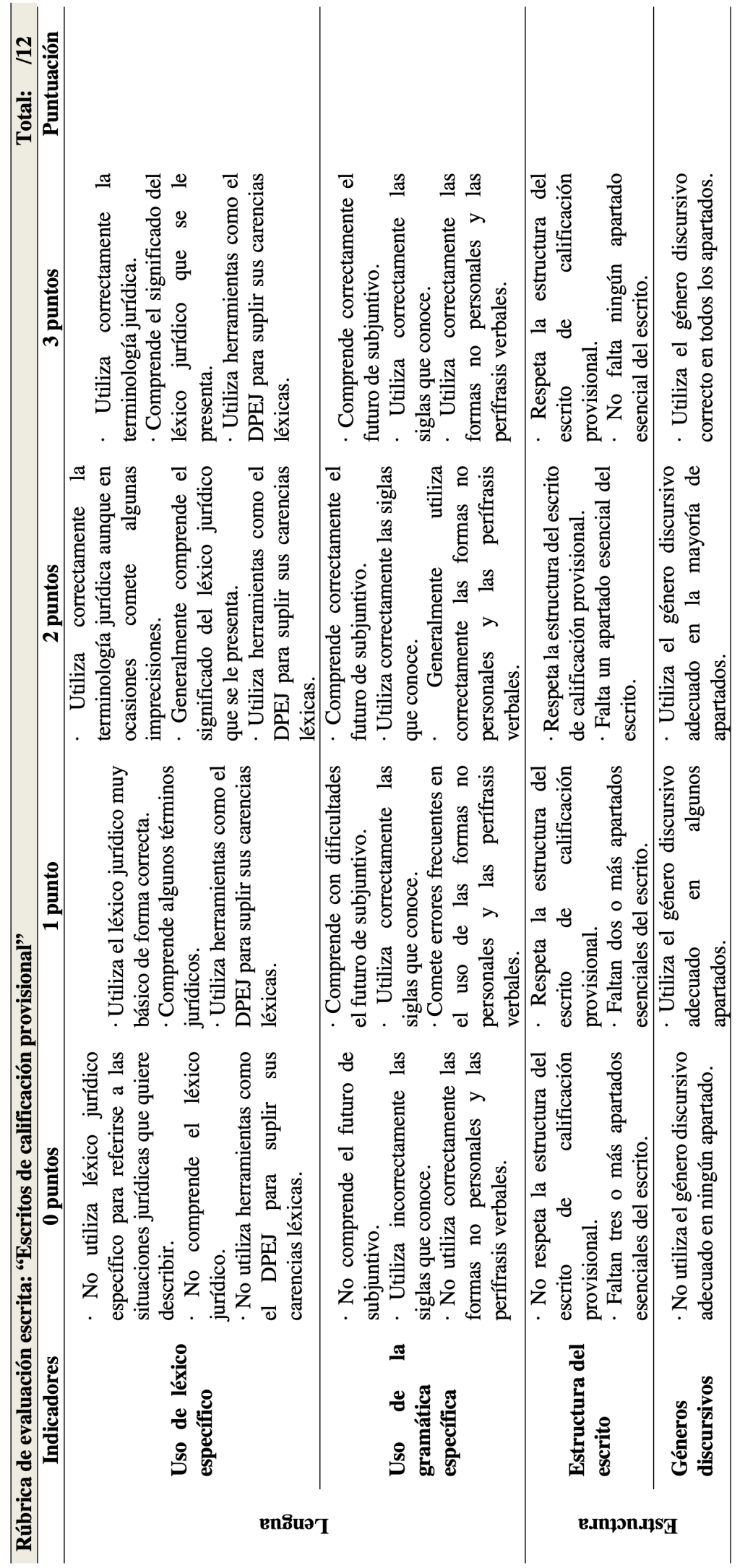

Revista de Lenguas para Fines Específicos 27.1 


\section{Anexo IX}

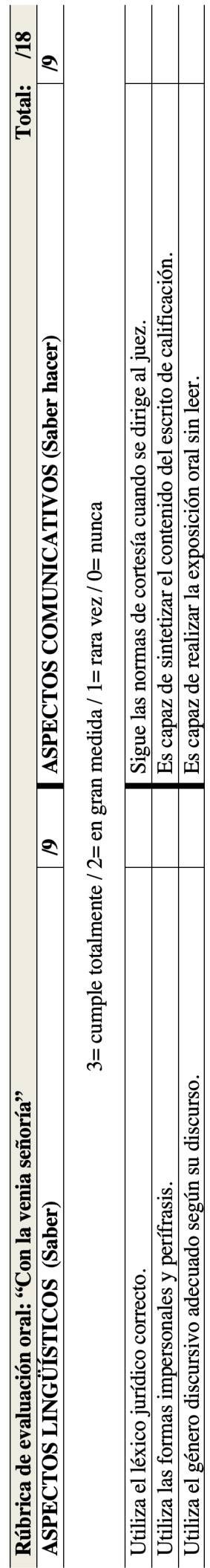

Revista de Lenguas para Fines Específicos 27.1 ISSN : 2340-8561 